\title{
Kebijakan Pendidikan Inklusi Sebuah Solusi di Sekolah Dasar
}

\author{
Muhamad Romadhon ${ }^{1 *}$, Arita Marini ${ }^{2}$, Mohamad Syarif Sumantri ${ }^{3}$ \\ Universitas Negeri Jakarta, Jakarta, Indonesia ${ }^{1}$ \\ Universitas Negeri Jakarta, Jakarta, Indonesia ${ }^{2}$ \\ Universitas Negeri Jakarta, Jakarta, Indonesia ${ }^{3}$ \\ *Corresponding author: muhammadromadon@gmail.com ${ }^{1}$
}

\begin{abstract}
Inclusion education policy is still considered not optimal in terms of its management and implementation. The purpose of this study is to determine the supporting and inhibiting factors in the policy of inclusive education in North Jakarta Sunter Jaya 03 public elementary schools, as well as what efforts or solutions have been attempted by school principals and teachers to overcome these problems. Based on the results of observations, documentation, and interviews, it can be seen that the supporting factors of the inclusive education policy in primary schools are the collaboration between school principals, teachers, education offices, and the community to support the implementation of inclusive education program. Although the implementation of inclusive education in primary schools still finds some obstacles, the principal, teachers, education offices and the community continue to work together to improve management and implementation in order to provide appropriate solutions and services for students in general and children with special needs. as an effort to improve the quality of education services in primary schools.
\end{abstract}

Keywords: inclusive education; policy; solutions

\begin{abstract}
ABSTRAK
Kebijakan pendidikan inklusi masih dipandang belum maksimal dilihat dari pengelolaan maupun implementasinya. Tujuan penelitian ini yakni mengetahui faktor pendukung dan penghambat dalam kebijakan pendidikan inklusi di sekolah dasar negeri Sunter Jaya 03 Jakarta Utara, serta upaya atau solusi apa yang telah diupayakan kepala sekolah dan guru untuk mengatasi masalah tersebut. Berdasarkan hasil observasi, dokumentasi, dan wawancara dapat diketahui faktor pendukung dari kebijakan pendidikan inklusi di sekolah dasar adanya kerjasama antara kepala sekolah, guru, dinas pendidikan dan masyarakat untuk mendukung berjalannya program pendidikan inklusi. Meskipun pada implementasi pendidikan inklusi di sekolah dasar masih ditemukan beberapa kendala, akan tetapi kepala sekolah, guru, dinas pendidikan dan masyarakat terus berupaya melakukan kerjasama untuk melakukan peningkatan pengelolaan dan implementasi agar dapat memberikan solusi dan layanan yang tepat bagi siswa pada umumnya dan anak berkebutuhan khusus sebagai upaya peningkatan kualitas layanan pendidikan di sekolah dasar.
\end{abstract}

Kata Kunci: kebijakan; pendidikan ınklusi; solusi

\section{Pendahuluan}

Nasib seorang anak berkebutuhan khusus ditentukan pada saat ia dilahirkan, kemungkinan dia akan bersekolah sangat kecil. Dari 10 anak tersebut, hanya satu yang kemungkinan besar menerima pendidikan dalam bentuk apapun. Meskipun sulit untuk didefinisikan secara memadai, pendidikan inklusi secara luas dapat dikonseptualisasikan sebagai pembentukan ruang belajar yang memungkinkan yang peduli dengan beragam kebutuhan pendidikan semua anak, terlepas dari faktor-faktor seperti ras, latar belakang sosial ekonomi, jenis kelamin, kecacatan, dan sebagainya (Sharma et al., 2019).

Pendidikan inklusi merupakan sistem penyelenggaraan pendidikan yang memberikan layanan dan kesempatan kepada semua anak tidak terkecuali anak berkebutuhan khusus dan 
anak dengan potensi kecerdasan atau bakat istimewa untuk mengikuti pendidikan dan pembelajaran dalam satu lingkungan bersama-sama anak dengan kriteria pada umumnya. Undang-Undang Dasar 1945 Pasal 32 ayat (1) telah menegaskan bahwa "setiap warga berhak untuk mendapatkan pendidikan"; pada Undang-Undang Dasar 1945 Pasal 32 ayat (2) menegaskan bahwa "setiap warga berhak dan wajib mengikuti pendidikan dasar dan pemerintah wajib membiayainya". Undang-Undang Nomor 20 Tahun 2003 Tentang Sistem Pendidikan Nasional, Pasal 5 ayat (1) yang menegaskan bahwa "setiap warga negara mempunyai hak yang sama untuk memperoleh pendidikan yang bermutu". Undang-undang inilah yang menjadi bukti kuat hadirnya pendidikan inklusi ditengah masyarah. Pembelajaran pada pendidikan inklusif mempertimbangkan prinsip-prinsip pembelajaran yang disesuaikan dengan karakteristik belajar peserta didik. Peserta didik yang memiliki kelainan fisik, emosional, mental, sosial, dan/atau memiliki potensi kecerdasan dan/atau bakat istimewa perlu mendapatkan layanan pendidikan yang sesuai dengan kebutuhan dan hak asasinya. Pendidikan khusus untuk peserta didik yang memiliki kelainan dan/atau peserta didik yang memiliki potensi kecerdasan dan/atau bakat istimewa dapat diselenggarakan secara inklusif (kemendikbud, 2009).

Pendidikan Inklusi masih dipahami sebagai upaya memasukkan anak berkebutuhan khusus ke sekolah regular dalam rangka memberikan hak atas pendidikan untuk semua anak, kemudahan akses pendidikan, dan menghilangkan diskriminasi. Dalam implementasinya guru cenderung belum mampu bersikap proaktif dan ramah terhadap semua anak, menimbulkan komplain orang tua, dan menjadikan anak berkebutuhan khusus sebagai bahan olok-olokan. Sekalipun sudah didukung dengan visi yang cukup jelas, menerima semua jenis anak berkebutuhan khusus sebagian sudah memiliki guru khusus, mempunyai catatan hambatan belajar pada masing-masing anak berkebutuhan khusus, dan kebebasan guru kelas dan guru khusus untuk mengimplementasikan pembelajaran yang lebih kreatif dan inovatif di kelas, namun cenderung belum didukung dengan koordinasi dengan tenaga profesional, organisasi atau institusi terkait. Keterlibatan orang tua sebagai salah satu kunci keberhasilan dalam pendidikan inklusi, belum terbina dengan baik (Ilahi, 2016).

Negara Indonesia telah lama menerapkan pendidikan inklusi, kegagalan dan keberhasilan pada sekolah dengan program pendidikan inklusi dalam melaksanakan proses pembelajaran di sekolah salahsatunya dipengaruhi oleh manajemen kebijakan pendidikan inklusi di sekolah tersebut. Maka dari itu dibutuhkan para pemimpin dan implementator yang mampu dan bersedia melaksanakan kebijakan program pendidikan inklusi tersebut. Apabila kebijakan tidak dijalankan dengan baik, maka akan terjadi kesenjangan implementasi di lapangan yang artinya ada perbedaan antara hukum yang tertulis dan praktik kebijakan di lapangan atau sekolah (Supriatini et al., 2020). Implementation gap dapat terjadi karena adanya faktor pendukung dan penghambat dalam manajemen kebijakan pendidikan inklusi di sekolah dasar. Dalam mengatasi Implementation gap diperlukan pendekatan dan upaya yang berfokus pada kualitas kebijakan sejalan dengan praktik di lapangan, sesuai dengan kebutuhan sasaran masyarakat.

Meskipun dukungan kebijakan nasional yang kuat dan deklarasi universal sangat penting dalam memungkinkan pendidikan inklusi, sistem sekolah tidak menjadi inklusif sebelum pemain kunci, yaitu guru, telah memperoleh sikap positif yang diperlukan serta keterampilan dan keyakinan yang diperlukan dalam kemampuan mereka untuk menerapkan 
pendidikan inklusi dengan sukses. Pendidikan inklusi yang sukses membutuhkan dukungan top-down (misalnya kebijakan) dan bottom-up (misalnya kemahiran guru dan pendidikan guru); dukungan dari salahsatunya saja tidak cukup (Moberg et al., 2020). Saat ini di sekolah dasar semakin banyak ditemui anak dengan kebutuhan khusus (ABK). Hal tersebut menjadi tantangan tersendiri bagi kepala sekolah dan guru sekolah dasar bahkan masyarakat sekitar. Kebijakan pendidikan inklusi masih dipandang belum maksimal dilihat dari pengelolaan maupun implementasinya. Peneliti mencoba memberi gambaran deskriptif mengenai kebijakan pendidikan inklusi di sekolah dasar, harapannya agar menjadi gambaran bagi peneliti selanjutnya dalam meneliti pendidikan inklusi di sekolah dasar.

\section{Metode Penelitian}

Penelitian ini menggunakan pendekatan kualitatif dengan metode deskriptif yang bermaksud mendalami dan menghayati suatu obyek mengenai kebijakan pendidikan inklusi di sekolah dasar negeri Sunter Jaya 03 Jakarta Utara. Penelitian kualitatif dengan metode deskriptif adalah metode yang menjelaskan atau mendeskripsikan suatu fakta, data, dan objek penelitian secara sistematis dan sesuai dengan situasi alamiah. Terkait hal yang diteliti, hasil penelitian lebih menekankan pada makna dari pada hasil, dan hasil penelitian tidak mengikat serta dapat berubah sesuai dengan kondisi yang dihadapi di lapangan penelitian dan diinterpretasikan dan dituliskan dalam bentuk kata-kata atau deskriptif berdasarkan fakta di lapangan (Anggito \& Setiawan, 2018). Metode kualitatif dirasa sangat sesuai untuk mampu menjawab tujuan penelitian ini yakni mengetahui faktor pendukung dan penghambat dalam kebijakan pendidikan inklusi di sekolah dasar negeri Sunter Jaya 03 Jakarta Utara, serta upaya atau solusi apa yang telah diupayakan kepala sekolah dan guru untuk mengatasi masalah tersebut. Sumber data dalam penelitian adalah subjek mengenai perolehan data yang telah didapat, yaitu kepala sekolah dan guru di sekolah dasar negeri Sunter Jaya 03 Jakarta Utara. Pengambilan data dengan menggunakan teknik observasi, wawancara via online whatsapp dan google meet serta dokumentasi.

\section{Hasil dan Pembahasan}

Program pendidikan inklusi di sekolah merupakan kebersamaan peserta didik di kelas dalam lingkungan dan layanan pendidikan yang sama, kebersamaan siswa normal dan anak berkebutuhan khusus di lingkungan sekolah diyakini akan membawa suatu pengaruh positif yang sangat konstruktif dan efektif untuk mengintegrasikan mereka dalam suatu kehidupan sekolah dan kemudian berlanjut di luar sekolah. Kehidupan di lingkungan masyarakat menuntut mereka dapat berbaur serta berinteraksi dengan masyarakat yang sangat beragam Untuk dapat hidup dalam lingkungan masyarakat dengan baik maka perlu menyiapkan mereka sejak belajar di sekolah menjadi suatu keharusan. Peserta didik normal maupun anak berkebutuhan khusus dapat belajar bersama, meskipun dengan hambatan dan perbedaan kemampuan yang mereka miliki (Kadir, 2015).

Siswa yang tidak terbiasa bergaul dalam keragaman majemuk di sekolah akan menjadi sulit bergaul dengan lingkungan masyarakat. Kebersamaan siswa di sekolah inklusi ditujukan pula untuk mereduksi kesenjangan agar mereka terbiasa hidup dalam keragaman, sehingga mereka saling mengenal, mengetahui, dan memahami tentang keberadaan setiap individu. 
Anak berkebutuhan khusus dapat memperoleh pembelajaran dalam hubungannya dengan peserta didik normal, demikian sebaliknya, bahwa peserta didik normal dapat belajar bagaimana mengembangkan sikap untuk bisa menerima kehadiran anak berkebutuhan khusus.

Interaksi antar siswa sebenarnya tidak hanya terjadi di sekolah, tetapi perkenalan mereka di sekolah akan berlanjut pada interaksi mereka di luar sekolah dalam bentuk komunikasi, silaturrahmi antar siswa, dan terkadang melibatkan orang tua serta keluarga, sehingga mereka dapat saling berbagi pengalaman dan pengetahuan. Hal ini dapat menjadi jalan bagi peserta didik normal maupun anak berkebutuhan khusus bahwa sekolah inklusi dapat menjadi model terapi dalam mengurangi kesenjangan kehidupan antara anak normal dan anak berkebutuhan khusus. Model pendampingan yang dilakukan di sekolah inklusi pada jam belajar atau jam khusus konseling peserta didik dapat menjadi kesempatan upaya pengobatan atau terapis bagi siswa. Meskipun pada pelaksanaannya masih terdapat faktor penghambat seperti masih minimnya guru pendamping pada sekolah dengan program pendidikan inklusi (Widyawati, 2017).

Pendidikan inklusi merupakan solusi bagi peserta didik anak berkebutuhan khusus untuk tidak mengalami tekanan psikologis karena keadaan yang menimpa dirinya. Mengangkat harkat dan martabat anak berkebutuhan khusus, merasa diterima dan tidak terpinggirkan dengan keadaan yang menimpa dirinya akan dapat mendorong aktivitas siswa lebih aktif serta dapat mengembangkan kreativitasnya. Lembaga pendidikan yang dapat merangkul dan menerima keragaman seharusnya melakukan reorientasi kurikulum, infrastruktur, maupun sistem pembelajaran yang kompatibel dengan kebutuhan individu peserta didik yang beragam (Kadir, 2015). Konsep education for all (pendidikan untuk semua) mengisayaratkan perlunya sekolah serta lembaga pendidikan mempersiapkan pendidik yang memiliki kompetensi dan pemahaman serta mampu mendidik dan mengajar setiap individu sebagai akibat bahwa human differences dan learning styles differences dianggap sebagai sesuatu yang alamiah dan normal.

Implementasi kebijakan sekolah inklusi di sekolah dasar perlu ditinjau secara meyeluruh agar diketahui apakah pendidikan inklusi yang telah diterapkan sudah berjalan dan sesuai dengan kebutuhan dan tujuan yang telah ditetapkan. Implementasi kebijakan pendidikan inklusi merupakan aktivitas dalam proses kebijakan publik yang menentukan apakah kebijakan itu bersentuhan dengan kepentingan pengguna serta dapat diterima oleh masyarakat. Dalam hal ini, dapat ditegaskan bahwa dalam tahapan perencanaan dan formulasi kebijakan yang dirancang dengan sebaik-baiknya, tetapi jika pada tahapan implementasinya tidak diperhatikan optimalisasi penerapannya, maka tentu tidak jelas apa yang diharapkan dari sebuah produk kebijakan itu. Pada akhirnya dapat dipastikan bahwa pada tahapan evaluasi kebijakan, akan menghasilkan penilaian bahwa antara formulasi dan implementasi kebijakan tidak seiring sejalan, bahwa implementasi dari kebijakan itu tidak sesuai dengan yang diharapkan, bahkan menjadikan produk kebijakan itu sebagai batu sandungan bagi pembuat kebijakan itu sendiri (Nurwan, 2019).

Implementasi pada Program Pendidikan dapat dikaji berdasarkan dua variabel menurut Merilee S. Grindle, dua variabel tersebut adalah variabel Isi Kebijakan dan Lingkungan Implementasi. Hasil dan pembahasan penelitian ditemukannya masalah dalam mengimplementasikan program pendidikan inklusi, akan tetapi permasalahan tersebut tidak 
menghambat jalannya proses implementasi program pendidikan inklusi di sekolah. Hasil penelitian menunjukkan bahwa implementasi program pendidikan inklusi telah berjalan dengan baik sesuai dengan target sasaran yang hendak dicapai atas kerjasama kepala sekolah, guru, dinas pendidikan dan masyarakat (Sudarto, 2016).

Berdasarkan hasil penelitian (Tarnoto, 2016) permasalahan yang muncul terkait implementasi program pendidikan inklusi adalah kaitannya guru, siswa, orangtua, sekolah, masyarakat, pemerintah dan masih kurangnya sarana prasarana yang mendukung pelaksanaan program sekolah inklusi. Hal ini juga dikarenakan kurang adanya kerjasama dari berbagai pihak. Guru merupakan faktor utama dalam proses pendidikan inklusi, tetapi tanpa adanya bantuan dari pihak lain pelaksanaan sekolah inklusi tidak bisa berjalan dengan maksimal, sehingga selain guru yang ditangani, perlu juga menumbuhkan budaya sekolah inklusi baik didalam sekolah itu sendiri ataupun komunitas diluar sekolah tersebut, selain itu kebijakan pemerintah juga sangat menentukan pelaksanaan sekolah inklusi.

Hal yang harus disiapkan di sekolah berbasis pendidikan Inklusi adalah guru (brainware), pengembangan kurikulum (software), serta sarana dan prasarana (hardware). Ketiganya perlu manajemen untuk bisa menciptakan lingkungan belajar yang bisa mendukung perkembangan anak (Alfina \& Anwar, 2020). Pelatihan dan pengembangan soft skill seorang pengajar terhadap anak berkebutuhan khusus (ABK), para guru mampu melakukan asesmen dan juga terapi untuk $A B K$, merancang pembelajaran serta memberikan layanan pendidikan ABK. Alat permainan edukatif juga dibutuhkan untuk mendukung terapi dan juga pendidikan mereka yang mempunyai kebutuhan khusus (Ariastuti \& Herawati, 2016). Pendidikan inklusi diharapkan dapat memberikan kontribusi yang besar kepada anak berkebutuhan khusus dalam bidang pendidikan, jadi tidak ada lagi anak berkebutuhan khusus yang tidak mendapatkan layanan pendidikan di sekolah (Agustin, 2017).

Berdasarkan hasil observasi, dokumentasi, dan wawancara dapat diketahui faktor pendukung dari kebijakan pendidikan inklusi di sekolah dasar adanya kerjasama antara kepala sekolah, guru, dinas pendidikan dan masyarakat untuk mendukung berjalannya program pendidikan inklusi. Kerjasama tersebut tercermin dalam kebijakan sekolah yang mendorong pelaksanaan program pendidikan inklusi yang terintegrasi dalam proses pembelajaran. Faktor pendukung tersebut menjadi keuntungan bagi sekolah dan lingkungan masyarakat serta siswa dalam berinteraksi, bersosialisasi dan toleran terhadap perbedaan di lingkungan sekolah maupun masyarakat.

Selain faktor pendukung dalam pelaksanaan program pendidikan inklusi tentunya ada faktor penghambat yang menjadi sebuah tantangan bagi kepala sekolah dan guru, masih ada paradigma pandangan masyarakat bahwa anak berkebutuhan khusus sulit untuk ditangani, sehingga menimbulkan adanya komplain dari beberapa orang tua murid yang keberatan anaknya disatu kelaskan dengan anak berkebutuhan khusus. Faktor penghambat lainnya masih kurangnya pengetahuan penanganan anak berkebutuhan khusus, dikarenakan guru bukan dari pendidikan luar biasa. Pada umumnya guru di sekolah dasar berasal dari program studi pendidikan guru sekolah dasar, sehingga memiliki keterbatasan informasi mengenai penanganan anak berkebutuhan khusus secara spesifik. Selain itu faktor penghambat dalam pelaksanaan program pendidikan inklusi adalah kurikulum yang belum berreorientasi disusun untuk program sekolah inklusi, sehingga hal tersebut menjadi kesulitan tersendiri 
bagi pendidik. Disamping itu sarana pendukung di sekolah belum cukup memadai untuk memfasilitasi anak berkebutuhan khusus.

Upaya kepala sekolah dan guru dalam implementasi pendidikan inklusi. Lembaga sekolah dan dinas pendidikan terus berupaya melakukan perbaikan dan mencari solusi untuk menangani hambatan yang terjadi pada pelaksanaan program pendidikan inklusi. Upaya yang sudah dilakukan diantaranya:

1. Sosialisasi yang dilakukan bersama komite sekolah sebagai upaya memberikan pemahaman dan peningkatan kesadaran pada seluruh orang tua murid di sekolah dasar tersebut;

2. Pelatihan dan workshop mengenai penanganan anak berkebutuhan khusus terus dilakukan sebagai upaya peningkatan mutu layanan pada implementasi program pendidikan inklusi dan sebagai peningkatan kompetensi guru;

3. Pihak sekolah bekerjasama dengan dinas pendidikan mengadakan pelatihan pengembangan model kurikulum dalam upaya reorientasi kurikulum bagi sekolah inklusi;

4. Sekolah terus berupaya melengkapi sarana pendukung untuk meningkatkan pelayanan pendidikan pada sekolah inklusi, dengan bekerjasama dinas pendidikan melalui pemerolehan bantuan dari pemerintah pusat untuk pemenuhan fasilitas pada sekolah inklusi.

\section{Kesimpulan}

Kebijakan pendidikan inklusi di sekolah dasar merupakan bentuk upaya pemerintah dalam membentuk generasi penerus bangsa agar dapat memahami dan menerima segala bentuk perbedaan serta menghindari sifat diskriminatif dalam kehidupan bermasyarakat. Dalam penyelenggaraannya peran kepala sekolah dominan menunjukkan keberhasilan pendidikan inklusi tersebut. Kepala sekolah sebagai leader dapat menentukan kebijakankebijakan yang strategis untuk menunjang keberhasilan program pendidikan inklusi. Dalam pengelolaan dan pelaksanaannya terdapat faktor pendukung serta penghambat yang mempengaruhi keberhasilan program tersebut. Kepala sekolah dapat melakukan kebijakan yang tepat untuk memberikan kesempatan dan mendorong guru dalam mengembangkan kompetensi, serta berkaitan dengan pengelolaan sarana prasarana yang masih perlu dilengkapi sesuai kebutuhan pada sekolah inklusi. Meskipun pada implementasi pendidikan inklusi di sekolah dasar masih ditemukan beberapa kendala, akan tetapi kepala sekolah, guru, dinas pendidikan dan masyarakat terus berupaya melakukan kerjasama untuk melakukan peningkatan pengelolaan dan implementasi agar dapat memberikan solusi dan layanan yang tepat bagi siswa pada umumnya dan anak berkebutuhan khusus sebagai upaya peningkatan kualitas layanan pendidikan di sekolah dasar.

\section{Daftar Pustaka}

Anggito, A., \& Setiawan, J. (2018). Metodologi penelitian kualitatif. Sukabumi: CV Jejak (Jejak Publisher).

Ilahi, Mohammad Takdir. 2016. Pendidikan Inklusif. Yogyakarta: Ar-Ruzz Media. 
$\begin{array}{lllll}\text { Peraturan } & \text { Kementrian } & \text { Pendidikan }\end{array}$ https://www.kemdikbud.go.id/main/blog/2019/07/kemendikbud-ajak-daerahtingkatkan-pendidikan-inklusif

Agustin, I. (2017). Manajemen Pendidikan Inklusi Di Sekolah Dasar Sumbersari 1 Kota Malang. Education and Human Development Journal, 1(1). https:/ / doi.org/10.33086/ehdj.v1i1.290

Alfina, A., \& Anwar, R. N. (2020). Manajemen Sekolah Ramah Anak Paud Inklusi. ALTANZIM: Jurnal Manajemen Pendidikan Islam, 4(1), 36-47. https://doi.org/10.33650/altanzim.v4i1.975

Ariastuti, R., \& Herawati, V. D. (2016). Optimalisasi Peran Sekolah Inklusi. Jurnal Pengabdian Pada Masyarakat, 1(1), 38-47. https:/ / doi.org/10.30653/002.201611.7

Kadir, A. (2015). PENYELENGGARAAN SEKOLAH INKLUSI DI INDONESIA Abd. Kadir (Dosen PAI FTK UIN Sunan Ampel Surabaya). Pendidikan Agama Islam, 03, 1-22.

Moberg, S., Muta, E., Korenaga, K., Kuorelahti, M., \& Savolainen, H. (2020). Struggling for inclusive education in Japan and Finland: teachers' attitudes towards inclusive education. European Journal of Special Needs Education, 35(1), 100-114. https://doi.org/10.1080/08856257.2019.1615800

Nurwan, T. W. (2019). Implementasi Kebijakan Pendidikan Inklusif di Sekolah Dasar. JESS (Journal of Education on Social Science), 3(2), 201. https://doi.org/10.24036/jess/vol3iss $2 / 176$

Sharma, U., Armstrong, A. C., Merumeru, L., Simi, J., \& Yared, H. (2019). Addressing barriers to implementing inclusive education in the Pacific. International Journal of Inclusive Education, 23(1), 65-78. https:/ / doi.org/10.1080/13603116.2018.1514751

Sudarto, Z. (2016). IMPLEMENTASI KEBIJAKAN PENYELENGGARAAN PENDIDIKAN INKLUSIF Zaini Sudarto Prodi Pendidikan Luar Biasa FIP Unesa Abstrak. Jurnal Pendidikan, 1, 89-97.

Supriatini, S., Muhdi, M., \& Yuliejantiningsih, Y. (2020). Implementasi Kebijakan Pendidikan Inklusi Di Sekolah Dasar Negeri Bolo Kabupaten Demak. Jurnal Manajemen Pendidikan (JMP), 8(3), 410-425. https:// doi.org/10.26877/jmp.v8i3.5400

Tarnoto, N. (2016). Permasalahan-Permasalahan Yang Dihadapi Sekolah Penyelenggara Pendidikan Inklusi Pada Tingkat Sd. Humanitas, 13(1), 50. https://doi.org/10.26555/humanitas.v13i1.3843

Widyawati, R. (2017). Evaluasi Pelaksanaan Program Inklusi Sekolah Dasar. Kelola: Jurnal Manajemen Pendidikan, 4(1), 109. https:/ / doi.org/10.24246/j.jk.2017.v4.i1.p109-120 